\title{
Who should know about our genetic makeup and why?
}

Tuija Takala and Heta Aleksandra Gylling University of Turku and Academy of Finland, respectively

\begin{abstract}
Recent developments in biology have made it possible to acquire more and more precise information concerning our genetic makeup. Although the most far-reaching effects of these developments will probably be felt only after the Human Genome Project has been completed in a few years' time, scientists can even today identify a number of genetic disorders which may cause illness and disease in their carriers. The improved knowledge regarding the human genome will, it is predicted, in the near future make diagnoses more accurate and treatments more effective, and thereby considerably reduce and prevent unnecessary suffering. On the other hand, however, the knowledge can also be, depending on the case, futile, distressing or plainly harmful. This is why we propose to answer in this paper the dual question: who should know about our genetic makeup and why? Through an analysis of prudential, moral and legal grounds for acquiring the information, we conclude that, at least on the levels of law and social policy, practically nobody is either duty-bound to receive or entitled to have that knowledge.

(Fournal of Medical Ethics 2000;26:171-174)
\end{abstract}

Keywords: Genetic testing; genetic screening; law; ethics; duties

Who has an interest in the knowledge, and on what grounds?

There are four groups of people who may want, or need, to know about our genetic composition. First, we ourselves can have an interest in being aware of all important aspects of our own health status, including the possibility that we nurture genetic disorders which can lead, later in life, to serious disease or early death. There are various studies on people's attitudes towards genetic testing. The ambiguity people have towards genetic knowledge in general seems to be the common result. When people are asked whether they would like to be tested they tend to say yes, but when it comes to actual testing, they are not, after all, too keen to participate. ${ }^{12}$ Second, there are a variety of people who are-or can become-genetically linked with us, and who can consequently have an interest in the knowledge. These include our fam- ily members and especially the individuals with whom we intend to have children. Third, individuals and groups with whom we have contracts, agreements and economic arrangements may well have an interest in knowing about our genetic makeup. This category embraces at least our employers, employees, banks, insurance companies and business associates. Fourth, society as a whole can have an interest in the composition of our genes, both because our health status can influence the contribution we make and because the public authorities may need the information to plan more efficient health care services. In each group the motives are different, and the cases for disclosing vary considerably in strength.

As regards the question of motivation, the term "should" in the question "Who should know?" can be interpreted in three ways. Prudentially speaking, to say that individuals should act in a specified manner is to say that the actions in question tend to promote the long term self interest of these individuals. From the viewpoint of morality, we should do what is right and avoid doing what is wrong. The rightness and wrongness of actions can be defined in different ways. The main moral theories connect the rightness of actions with the observance of virtues, the fulfilment of moral obligations and the avoidance of harm. When it comes to legal thinking, it is held in most liberal societies that countering harm to others should be the primary, if not the only, justification for the use of coercion and constraint.

\section{Should people know about their own genetic makeup?}

Genetic disorders range from the fatal to the trivial, and from the blatantly obvious to the virtually unseen. People who have fair skin have a greater inherited tendency to develop skin cancer than people whose complexions are darker, but this condition is seldom seen as a threatening genetic disorder. The prudential case in favour of knowing about one's genes can be put in its strongest form by studying a genuinely dangerous and universally frightening, instead of an unrecognised, affliction. 
Individuals, for instance, whose tumour suppressor gene $p 53$ has undergone a certain mutation carry a disorder known as the LiFraumeni Syndrome, which predisposes them to a spectrum of cancers. The syndrome burdens the individuals with a fifty per cent risk of developing an invasive form of cancer by the age of thirty-a ninety per cent risk by the time they are seventy. While some of these cancers are, as such, curable, it is the accumulation and repetition to which the mutation predisposes individuals which, in the end, makes it lethal. ${ }^{3}$ The prudential question is: should people know about conditions like this for their own sakes? One answer is that the knowledge would be beneficial, as it would enable individuals to draw up their life plans realistically. Another response, however, is that if the information does not help people to improve their present or future physical condition, it is not only unwise but also unkind to make them aware of their true condition. It seems that especially when the condition is incurable people cannot have an automatic prudential obligation to acquire the information.

Let us suppose, however, that the disorder is potentially fatal but curable or preventable if diagnosed at an early stage. Assuming that individuals want to live long and healthy lives, it would seem prudential for them to know about such a dormant condition. But there are two different kinds of case here. If the disorder can be removed, and the ensuing disease prevented, by one simple operation which does not pose serious risks to the patient, then all right-minded people have firm prudential grounds for finding out about the condition of their genes. If, however, the treatment is ineffective, painful or difficult to come by, the grounds are less firm.

An additional aspect is that diseases are seldom the result of genetic disorders alone-there are also environmental, psychological and social factors which can contribute to the emergence of basically hereditary ailments. When the prevalence of the actual illness depends on these other factors, it can be argued that people should know about their genetic weakness because the knowledge enables them to adjust their lifestyles accordingly. On the other hand, however, it can also be argued that if there is little the individuals themselves can do to alter their circumstances, the information would be needlessly distressing. And even if they could alter their lifestyles, it is not clear that the knowledge is a blessing, since people may enjoy their lives as they are and resent the idea of changing their behaviour.

The relevant moral considerations regarding our duty to know about our genetic makeup include our virtues and duties, and the possible harm inflicted on others by the lack of knowledge. From the viewpoint of virtue ethics it can be argued that persons of integrity should not be involved in any kind of self-deception, and that they should not, therefore, deliberately overlook facts about their own health status. Those who emphasise our duties, in their turn, can state that we have an obligation to protect others, and those who confine their attention to the undesired consequences of our choices can argue that we should not inflict harm on others either by acts or by omissions if this can be reasonably avoided. But whom and to what degree should we protect from unpleasantness and harm?

If we plan to have children, there are cases in which we have a clear moral duty to find out about the genetic disorders that we carry. Our future children are entitled to be protected from a disease which causes suffering but which could easily have been cured or prevented prior to their birth or in their early infancy. The case of incurable conditions is more difficult to tackle. Some theorists think it would be wrong to bring into existence an individual who suffers from a genetic ailment, when the alternative would have been to give birth to another individual who is healthy. Others argue that even a life which contains some suffering is better than no life at all, and that the potential individuals who are not given the chance to live are therefore wronged by the decision not to bring them into existence.

Although all main branches of ethics seem to oblige us to know about our genetic makeup, at least in some cases, no legal duties can be derived from these obligations. People cannot really be forced into moral integrity, and the harm inflicted on future children by lack of genetic knowledge cannot really be regulated with any accuracy. Parents can conceivably be blamed and even punished for harming their unborn or newly born children by direct physical violence, but it would be far too complicated to prove that a genetic disorder results from a malicious, negligent and deliberate decision not to know about one's genes.

\section{Should our reproductive partners or business associates know?}

The individuals with whom we intend to have children and our business associates both have, in their parental or professional roles, good prudential grounds for finding out about our genetic disorders. Our reproductive partners can legitimately try to ensure that the offspring we produce are healthy and do not have to suffer unnecessarily from hereditary diseases. The individuals with 
whom we have business relations have a wellfounded interest in knowing whether we are able to keep our promises and fulfil our obligations.

The moral case our reproductive partners have for acquiring information concerning our genes is strengthened by the interests of our prospective children to be healthy, but it is also weakened by the fact that individuals have no moral obligation to produce offspring with other specified individuals. Our partners can have a moral obligation to avoid bringing into existence a child whose genetic disposition makes her or his life miserable, especially if the alternative is to have a healthy child. But this obligation can be discharged by choosing another partner, as it is nobody's duty to have children with us. If harm might befall us should our genetic disorders be revealed, our reproductive partners can have no overall moral, let alone legal, right to know about them.

Economic considerations can make it desirable for our employers, employees, business associates and insurance companies to find out what genetic disorders we carry. Since some of our hereditary weaknesses, such as the mutation of gene $p 53$, are potential causes of disabling illness and premature death, contracts and agreements which are made with us without knowing about such conditions can be highly unprofitable. These reasons can be seen as prudential or moral, depending on who will be harmed by our inability to fulfil the contracts. If only our direct business associates are harmed, then the reason is prudential; if the harm is extended to their shareholders, clients and employees, then the grounds for disclosure are moral.

But the obligation to protect others against economic loss is not as strict as the duty not to inflict suffering on innocent individuals. All economic decision making is based on risk assessment, and from the point of view of our business associates the composition of our genes is only one unknown factor among others in the cost-benefit analysis. Many people would, of course, like to ascertain the state of our genes, but if this interest is founded on a desire to maximise economic profits, then almost any reluctance that we may have against parting with the information provides, both morally and legally speaking, a sufficiently good reason not to satisfy their curiosity. Grounds for such reluctance can be found in the distress that the knowledge can cause, and in the fear of discrimination which can accompany the disclosure of our medical status to others.

The representatives of insurance companies can argue that if we do not report our genetic disorders when we apply for life or health policies, other policyholders will be unjustly burdened by the unforeseen cost of our medical treatment and premature death. If this argument is presented in the framework of consequences and harm, then the economic loss possibly inflicted on others is outweighed in a level-headed comparison by our own distress caused by the unwanted knowledge and our fear of discrimination. It can also be argued that life and health policies should not be made more expensive for those who carry mutated genes, because many other factors besides the biological determine whether people actually get ill or not. Genetic disorders cannot always be seen as diseases in their early stages. An obvious injustice related to differential insurance practices is that they punish those who are already genetically worse-off by denying them life and health policies, or by enlarging the payments. ${ }^{4}$

The insurers' appeals to justice can also be founded on the reciprocity of duties and rights favoured by many moral philosophers. It can be held that we should not do to others what we would not like them to do to us, and that when we profit at other people's expense by refusing to disclose our genetic weaknesses we are violating this principle. The problem with this argument is that it is not normally considered unjust to collect a compensation when the terms of the policy are met. Insurance companies define the payments of life and health policies on the basis of epidemiological data, and the expenses caused by known genetic disorders should already have been accounted for, at a general level, in the fees.

The only way to benefit unfairly at the expense of others would be, within the duty-based approach, wilfully to conceal one's genetic condition from the underwriter. This is wrong within ethical views which absolutely condemn lying. The model applies to situations where would-be policyholders are explicitly asked by the insurance company to reveal the genetic disorders they know they have. But this kind of thinking creates more problems than it solves. Since individuals cannot have a legal duty to know about the condition of their genes, the prohibition against active lying generates a duty to tell only for those who have voluntarily acquired the information, and for those who have been informed against their will. As for the latter group, a special legal duty to be truthful would be grossly unfair in view of the fact that members of this group would already have been victimised once if they had been tested without consent. ${ }^{5}$ For those who have voluntarily tested themselves, the legal obligation to tell the truth would be equally indecent. It is, after all, in the best interest of society that its members freely acquire information about their health status. The 
duty of honesty would, however, make it more profitable for individuals to remain in ignorance.

Should our health care providers know?

Those who cater for our health care needs have at least two good reasons for wanting to know about the composition of our genes. Physicians can monitor our health-related needs more effectively and offer more reliable treatments if they are fully informed about all the relevant facts. And public health authorities can collect knowledge regarding the genetic makeup of the population, and plan in advance health care services which are likely to meet the future needs of citizens.

The Hippocratic tradition requires physicians to be beneficent, that is, to provide their patients with the best treatment available. ${ }^{6}$ Doctors can refer to this tradition and argue that in order to fulfil their duties they should be allowed to know about the genetic disorders of their patients. But the significance of beneficence has been undermined by the introduction of the principle of autonomy to health care ethics. The principle of autonomy states that medical professionals ought to respect the self-determined, self-regarding choices of their informed and competent patients even if the choices in question are potentially harmful..$^{7}$ According to this maxim, people are entitled to remain in ignorance concerning their genetic disorders, which means that physicians cannot use paternalistic arguments to back their claims that they should be informed about their patients' condition. ${ }^{9}$

The work of public health authorities is often based on epidemiological data which is acquired by gathering information about the health and illness of citizens. If this work promotes human wellbeing and reduces human suffering, then we are, to some degree at least, morally obliged to reveal facts which can help the authorities. Furthermore, if we believe that other people should not hinder public health programmes by withholding personal information, then we too have an initial duty not to withhold information concerning ourselves. When it comes to absolutely binding moral duties and legally enforced obligations, however, the situation is different. The harm inflicted on others by the nondisclosure of genetic data is indirect and uncertain, while the harm inflicted on individuals with genetic disorders in the form of distress and discrimination is direct and tangible. The argument from the reciprocity of obligations is no more convincing. In an ideal world we would, no doubt, like individuals to do their best to help the public authorities in their attempts to provide better health care services. But in an ideal world we would not have to live in fear of discrimination should we reveal our genetic ailments to our potential employers or insurance companies.

\section{Who should know?}

Who, then, should know about our genetic makeup, and why? If the picture given in this paper is not distorted, we ourselves can have both prudential and moral reasons for knowing about some of our possible genetic disorders. Our reproductive partners, business associates and health care providers have similar reasons for acquiring the information. But when it comes to duties and rights which could be enforced by law, these reasons are not firm enough to support them. As long as people whose genes deviate from those of the average individual are likely to face suspicion and discrimination, societies cannot legitimately force people to know about their hereditary composition.

\section{Acknowledgements}

Our thanks are due to Veikko Launis, University of Turku, and to two anonymous referees of the fournal of Medical Ethics for helpful comments.

Tuija Takala, Msc(soc), is a Research Fellow in the Department of Philosophy, University of Turku, Finland. Heta Aleksandra Gylling, $B A, M A$, $\mathrm{MSc}(\mathrm{soc}), \operatorname{LicSc}(\mathrm{soc}), \mathrm{DSc}$ (soc), is a Senior Research Fellow at the Academy of Finland and a Docent of Practical Philosophy at the University of Helsinki, Finland.

\section{References and notes}

1 Mitchell J, Scriver CR, Clow CL, Kaplan F. What young people think and do when the option of cystic fibrosis carrier testing is available. Fournal of Medical Genetics 1993;30:538-42.

2 Tambor ES, Bernhardt BA, Chase GA, Faden PR, Geller G, Hofman KJ, et al. Offering cystic fibrosis carrier screening to an HMO population: factors associated with utilization. American fournal of Human Genetics 1994;55:626-37.

3 Malkin D, Li FP, Strong LC, Fraumeni JF Jr, Nelson CE, Kim $\mathrm{DH}$, et al. Germ line p53 mutations in a familial syndrome of breast cancer, sarcomas, and other neoplasms. Science 1990; 250:1233-8.

4 250:1233-8. London: Routledge \& Kegan Paul, 1985: 87-110.

5 On the nature and significance of informed consent in genetic testing see, for example, Juengst ET. Genetic diagnostics. In: Fischer EP, Klose S, eds. The diagnostic challenge, the human gischer EP, Klose S, eds. The diagnostic challenge, the human genome.

6 Beauchamp TL, Childress JF. Principles of biomedical ethics [4th ed]. New York and Oxford: Oxford University Press, 1994: ch. 5. 7 See reference 6:59-105.

8 Häyry H. The limits of medical paternalism. London and New York: Routledge, 1991: ch 7 .

9 See reference 8:154-5. 